\title{
Orgânico e inorgânico em "Sobre a vontade na natureza"
}

\author{
Organic and inorganic "On the will in nature"
}

\author{
Ana Carolina Soliva Soria \\ Pós-doutoranda em Filosofia pela FFLCH/USP \\ Agência financiadora: FAPESP \\ E-mail: anasoliva@,bol.com.br
}

Resumo: O presente artigo pretende analisar alguns aspectos em que o texto Astronomia Física, apresentado em "Sobre a vontade na natureza", ajuda-nos a compreender as relações entre a natureza orgânica e inorgânica na obra de Schopenhauer.

Palavras-chave: Vida; Causalidade; Forma; Matéria.

\begin{abstract}
This article aims at examining some aspects in which the text of the Physical Astronomy, presented in the book "On the Will in Nature", could help us to understand the relation between organic and inorganic nature in Schopenhauer's work.
\end{abstract}

Keywords: Life; Causality; Form; Matter.

Astronomia física, quarto dos textos que compõem a obra "Sobre a vontade na natureza", não se limita a tratar apenas das relações entre os corpos celestes e a maneira como a gravidade dita o ritmo do minueto em que bailam, com elegância, no espaço cósmico. Para além disso, ao investigar a origem do movimento dos mais diferentes elementos que compõem a natureza, Schopenhauer traça uma analogia entre a atração gravitacional, os efeitos do calor e da luz, da eletricidade e oxidação sobre os corpos, o crescimento das plantas e as ações dos seres dotados de conhecimento. Todos os fenômenos da natureza são colocados lado a lado, não sendo possível descartar, para nenhum deles, as relações de causalidade entre a origem e o efeito dos movimentos. Ao traçar esse quadro geral que nos leva, como em todos os outros textos que compõem a referida obra, ao seu pensamento único, encontramos uma afirmação bastante interessante e na qual gostaríamos de nos deter, a saber: "Vivo e orgânico são conceitos recíprocos; com a morte cessa o orgânico de ser como tal" ${ }^{2}$. A identificação entre vivo e orgânico, que hoje pode nos parecer muito evidente, era bastante problemática para os pensadores do final do século XVIII e início do XIX. Não é aqui nossa intenção examinar o percurso das concepções de vida e organismo na história do pensamento e, por esse motivo, deixaremos de lado tal problemática. No presente estudo, pretendemos nos fixarmos nos textos de Schopenhauer e expor, ainda que de maneira bastante breve, as consequências da identificação entre vida e organismo. Para

\footnotetext{
${ }^{1}$ Uma primeira versão desse texto foi apresentada no XV Encontro Nacional da ANPOF.

${ }^{2}$ Schopenhauer, A. N, SW III, p. 407 (As traduções das citações são de nossa responsabilidade).
} 
isso, nossa exposição está dividida em dois momentos: primeiramente, trataremos do problema da causalidade nos diferentes graus de objetivação dos seres; em seguida, tomando como base as informações contidas na primeira parte, passaremos para o exame da concepção de vida. Os textos sobre os quais fundamentamos a nossa exposição são o $4^{\circ}$ capítulo de Sobre a vontade na natureza e o $23^{\circ}$ dos complementos ao Mundo como vontade e representação, intitulado "Sobre a objetivação da vontade na natureza desprovida de conhecimento".

\section{Causa, excitação e motivo na escala dos seres}

Das diferentes maneiras como a lei da causalidade se manifesta na natureza, Schopenhauer distingue os diferentes reinos: animal, vegetal e mineral ${ }^{3}$. Vale notar que a classificação dos seres é acompanhada da distinção de três modos de expressão da lei da causalidade, a saber: o motivo (no animal), a excitação (no vegetal) e a causa (no mineral).

Segundo Schopenhauer, se percorremos a natureza em seus diferentes graus de objetivação, vemos que quanto mais baixo se está na escala dos seres, melhor pode ser percebida a relação causal entre os fenômenos. Em "Astronomia física", o mais alto exemplo da compreensibilidade da causalidade é, para o filósofo, o movimento que é transmitido no choque entre duas bolas. Nesse caso, causa e efeito são completamente homogêneos e uniformes: a causa do movimento da bola que recebe a colisão de outra é o movimento da bola que a ela se chocou. Essa clareza é encontrada, segundo ele, em todos os efeitos puramente mecânicos da natureza. Nos fenômenos elétricos e químicos ${ }^{4}$, por mais que o grau de homogeneidade e uniformidade não seja tal como nos eventos mecânicos, pois o calor que amolece a cera, por exemplo, endurece a argila, é ainda assim possível determinar com êxito leis para tais eventos. No parágrafo 23 de $O$ mundo como vontade e representação, Schopenhauer descreve a relação entre causa e efeito para os fenômenos mecânicos, elétricos e químicos da seguinte maneira:

[...] na causa genuína, o efeito cresce exatamente na mesma proporção que a causa, que é a mesma da reação; assim, se o modo de ação é conhecido, o grau do efeito é medido e calculado pelo grau de intensidade da causa, e também o inverso. Essas causas propriamente ditas agem em todos os fenômenos da mecânica, da química etc., sucintamente: em todas as modificações dos corpos inorgânicos 5 .

Schopenhauer fala de uma relação de proporção (Verhältnis) entre o efeito e a causa: a intensidade da causa é proporcional ao seu efeito, e aumentando-se a intensidade da primeira,

${ }^{3}$ Distinção encontrada no $\S 23$ d'O mundo.

${ }^{4}$ São exemplos de fenômenos elétricos e químicos: o efeito de oxidação das placas de uma pilha e o da dilatação, liquefação, volatilização e cristalização dos corpos pelo calor.

${ }^{5}$ SCHOPENHAUER, A. $W W V, S W I, \S 23$, p. 177, grifo nosso. 
aumenta-se consequentemente o segundo. Nos corpos inorgânicos, a relação causal se dá de modo direto, necessário e evidente, e pode ser expressa por princípios e leis capazes de recobrir a repetição dos mesmos eventos. Todas as vezes que o calor incidir sobre a cera, p. ex., ela se amolecerá. Os fenômenos inorgânicos podem, assim, ser descritos de maneira precisa, uniforme e homogênea.

Por outro lado, ao subirmos dos eventos mecânicos, elétricos e químicos para os da existência vegetal, é possível observar, segundo Schopenhauer, que na planta a igualdade entre ação e reação já não é tão evidente quanto nos corpos inorgânicos. Ou melhor, a relação direta e necessária que havia nestes entre ação e reação é anulada nos vegetal. Ainda no parágrafo 23 d'O mundo lemos:

[...] chamo excitação aquela causa que não sofre nenhuma reação que corresponda à sua própria ação, e cuja intensidade não se move de modo algum paralelamente ao grau de intensidade do efeito, que não pode, por consequência, tornar-se medida. [...] Todo efeito sobre um corpo organizado é desse tipo ${ }^{6}$.

A relação entre ação e reação torna-se, nos corpos organizados, muito menos evidente e muito mais misteriosa do que nos corpos não organizados, uma vez que não se pode mais estabelecer neles proporção exata entre causa e efeito. O equilíbrio entre a quantidade de força da ação e da reação perde aqui a sua eficácia e revela-se para nós de modo incomensurável. Se a possibilidade da medida entre ação e reação nos permitia conhecer o mundo não organizado segundo leis gerais (allgemeinen Gesetzen), nos corpos organizados, esse conhecimento será progressivamente (isto é, nas plantas em menor grau, nos animais em grau intermediário e nos homens em máximo grau) menos visível.

O que Schopenhauer afirma é que as leis gerais, uma vez que dependem da proporção entre causa e efeito, somente podem ser estabelecidas na e pela homogeneidade entre a primeira e o segundo. Essa homogeneidade, que vigora nas relações entre os corpos não organizados, é o que desaparecerá na existente entre os corpos organizados, e nos revela a incapacidade de se expressar o heterogênio nas leis gerais. Se o movimento da linfa nas plantas, por exemplo, é explicado com base na hidráulica e na capilaridade, isso não se deve ao fato de se pode identificar excitação e causa, e explicar os eventos dos corpos organizados por relações limitadas e fixas, mas por uma dissolução da heterogeneidade da relação de causalidade, que limita e fixa a própria compreensão das relações orgânicas.

A homogeneidade ou heterogeneidade das relações causais nos corpos está em conformidade com a potência de individualidade do corpo em que ela se manifesta. Tal como afirma Schopenhauer, a potência de individualidade dos corpos não organizados é mínima. Nas plantas, essa potência é maior

\footnotetext{
${ }^{6}$ SCHOPENHAUER, A. $W W V, S W I, \S 23$, p. 177.
} 
do que nos inorgânicos, e nos animais, ainda maior que nas plantas. O homem é o único dentre todos os seres dotado de máxima potência de individualidade.

Tendo isso em vista, a relação entre individualidade e determinação é de inversão: quanto maior a potência de individualidade, menor é a possibilidade de determinar mediante leis gerais as relações entre ação e reação. Ou ainda, menor é a nossa compreensão entre a ação e o efeito da ação. Em "Astronomia física", Schopenhauer afirma que inúmeros são os mistérios existem entre a semente e a planta crescida, que muitas são as plantas que se banham no mesmo sol e na mesma água e muito pouco podemos compreender essa diversidade ${ }^{7}$.

Ao tomarmos os seres dotados de conhecimento, a compreensão da diversidade se torna ainda menor que nas plantas. Ao afirmar, ainda em "Astronomia física”, que o motivo é a causa mediada pelo conhecimento, Schopenhauer não tem em vista apenas o homem, capaz de conhecer abstratamente, mas também os animais, que conhecem intuitivamente. E como dentre todos os seres o homem é aquele cuja individualidade aparece em seu maior grau, um mesmo motivo age diferentemente em cada um, impossibilitando dar às ações humanas o mesmo nível de previsibilidade dos corpos não organizados. Mediado pelo conhecimento (não apenas intuitivo, como nos animais, mas também abstrato, dado pela razão), o homem leva em conta inúmeras circunstâncias em seu agir e a reação a um motivo somente pode ser conhecida quando efetivamente realizada (jamais antecipada por leis gerais de causa e efeito). O grau de imprevisibilidade da reação é tão grande nos homens e o cumprimento da causalidade tão obscuro que pode parecer para as mentes mais rudes, afirma o filósofo, que não exista causa alguma das ações humanas, como se o ato voluntário não dependesse de nada, isto é, como se fosse sem fundamento e, portanto, livre. Contudo, explica-nos o filósofo, a motivação, como causa de uma ação, é um correlato subjetivo da lei da causalidade que rege todos os eventos do mundo fenomênico, a saber: a excitação nas plantas e a causa no inorgânico. Toda ação, considerada desde a atração entre os corpos celestes até a reflexão dos seres racionais, deve ser tomada como efeitos de uma causa, por maior que possa parecer, para nossa intelecção, a separação entre ação e reação. Se para os seres não organizados causa e efeito se encadeiam de maneira mais evidente, para os organizados a intimidade entre ação e reação é progressivamente mais obscura, atingindo o seu ponto máximo no homem.

\section{A reciprocidade entre as concepções de vida e organismo}

$\overline{{ }^{7} \text { Cf. SCHOPENHAUER, A. } N}, S W I I I$, p. 411 et seq. 
A crescente obscuridade da relação causal na escala dos seres nos põe assim a seguinte pergunta: haveria um movimento contínuo de transição entre mineral, vegetal e animal? É possível passar do mineral para o vegetal, e deste para o animal numa continuidade crescente? O estímulo seria um elemento de transição entre a causa e o motivo e a possibilidade de passar do mineral ao vegetal e deste para o animal? Ou ainda, Schopenhauer aceitaria de modo rigoroso a divisão da natureza em três reinos? A esse respeito, escreve o filósofo alemão:

De fato, a fronteira entre o orgânico e o inorgânico é a mais rigorosamente estabelecida em toda a natureza e talvez a única que não admite transição; de modo que "natura non facit saltus" [a natureza não faz saltos] parece aqui sofrer uma exceção. Ainda que muitas cristalizações mostrem semelhança externa com uma figura vegetal, existe ainda uma diferença fundamental e essencial entre o mais diminuto líquen, o mais humilde bolor e todo inorgânico ${ }^{8}$.

Essa passagem, extraída do complemento ao Mundo, capítulo 23 (Sobre a objetivação da vontade na natureza desprovida de conhecimento), nos mostra que a antiga divisão da natureza em reinos distintos (a saber: mineral, vegetal e animal), que vigorou, segundo Huneman ${ }^{9}$, de maneira bastante proeminente nos pensadores dos séculos que precederam Schopenhauer, já não encontra traços profundos em seu pensamento. Apesar das sabidas discordâncias que o filósofo alemão nutria pelas ideias de Lamarck, ambos concordam com uma divisão geral dos seres em orgânico e inorgânico - divisão que, aliás, foi muito explorada por outro autor de origem francesa pelo qual Schopenhauer nutria profunda admiração, a saber: Xavier Bichat.

Certamente Schopenhauer não quer com isso confundir animal e vegetal. O fato de o animal possuir uma vida vegetativa não nos permite identificá-los ou identificar motivo e excitação. Animal e vegetal são seguramente separados em sua filosofia: uma vez que, por exemplo, na planta não há mediação temporal (pois esta não tem representação), o estímulo excitatório é seguido imediatamente do ato orgânico - crescimento, excreção, digestão, circulação e reprodução. Animal e planta estão separados, mas não por um abismo tal como entre aquele distancia seres organizados e não organizados. Entre planta e animal, Schopenhauer afirma que há um contínuo e progressivo caminho.

A diferença entre orgânico e inorgânico não se refere aos aspectos exteriores de sua conformação, já que animal, planta e mineral podem apresentar semelhanças (tais como certas formações de corais, os ramos de uma árvore e a aparência de certos cristais), mas aos aspectos internos ao ser, que constituirão essencialmente a diferença entre orgânico e inorgânico e que, ao mesmo tempo, os coloca em uma relação de antítese. Schopenhauer escreve:

\footnotetext{
${ }^{8}$ SCHOPENHAUER, A. $W W V$, SW II, p. 382.

${ }^{9}$ HUNEMAN, P. Métaphysique et biologie, p. 21. 
No corpo inorgânico, o essencial e durável, por conseguinte, aquilo sobre o qual sua identidade e sua integridade se baseia é a substância (Stoff), a matéria (Materie); a parte não essencial e variável é, ao contrário, a forma (Form). No corpo orgânico se passa exatamente o inverso: pois é justamente na modificação constante da substância (Stoff) sob a permanência da forma que consiste sua vida, isto é, sua existência (Dasein) enquanto orgânico ${ }^{10}$.

Com isso, temos que a condição essencial do corpo organizado não é a conservação de sua matéria ao infinito, mas um processo de modificação constante desta, em conjunto com a conservação de sua forma. Entre orgânico e inorgânico estabelece-se uma relação de inversão entre forma e matéria. A agitação que caracteriza os corpos organizados não é aquela da passagem de uma forma a outra - própria do inorgânico -, mas na identidade de uma organização que, exatamente pela modificação da matéria, vem a ser orgânica. O organismo conta assim com um processo contínuo, coerente do início ao fim, que só termina com a morte, isto é, com o término desse processo ou desse modo de agitação.

Tal como já dissemos no início de nossa exposição, organismo e vida são identificados na filosofia de Schopenhauer. A vida não é um produto de forças inorgânicas - combustão, eletricidade, elasticidade, ou quaisquer propriedades mecânicas, elétricas ou químicas - e não pode ser atribuída a nenhuma modificação do reino inorgânico (às modificações ocorridas no globo terrestre, ao movimento dos corpos celestes e assim por diante). A qualidade de vivo pode apenas ser atribuída aos seres orgânicos.

Além disso, podemos dizer que nos corpos organizados, o jogo entre matéria e forma é o ponto comum entre o diverso, sem que se perca a heterogeneidade da relação. A vida se encontra não em uma lei geral, homogênea e fixa, mas em um princípio não determinado de organização interna ao corpo.

O fato da vida não ser dada na relação entre causa e efeito não é, entretanto, obstáculo para a compreensão da organização do corpo. A organização do corpo vivo não está em uma parte do ser (no cérebro ou no coração, por exemplo), ou em um princípio ou força que reside em uma parte do organismo (no sistema circulatório, por exemplo); ao contrário, está generalizada em todas as partes que compõem o corpo. Tendo isso em vista, Schopenhauer diferencia agregado ou composto e organismo: "Ora, todo organismo é de parte a parte orgânico, é orgânico em todas as suas partes, e em nenhuma delas, mesmo em sua menor partícula, é composto por agregado inorgânico." ${ }^{11}$ Com isso, não queremos dizer que no organismo não agem forças físicas e químicas, mas o que o mantém unido e o

\footnotetext{
${ }^{10}$ SCHOPENHAUER, A. $W W V, S W I I$, p. 383.

${ }^{11}$ SCHOPENHAUER, A. $W W V, S W I I$, p. 383. 
conduz em seu jogo entre forma e matéria é uma força vital (Lebenskraft) - esta é responsável por dominar as forças físicas e químicas que agem no organismo e querem modificar a forma e cristalizar a matéria. A força vital subordina as outras forças (inorgânicas) a si mesma e conserva a forma do organismo na variabilidade da matéria.

Para concluir o presente texto, gostaríamos de salientar que se Schopenhauer identifica vida a organismo e institui um abismo entre orgânico e inorgânico, não resta dúvida de que a vontade não pode ser atribuída apenas a um dos lados dessa divisão. Sua filosofia, como um pensamento único, encontra na vontade a unidade de toda matéria, seja ela viva ou morta, unidade metafísica, para a qual o físico, o químico, o biólogo apontam sem jamais poder encontrar. A hipótese de uma duplicidade dos corpos - como vontade e como representação - não se estende apenas aos viventes, mas a toda a natureza. Orgânico e inorgânico, ou ainda, vivo e não vivo nos revelam as possibilidades de mobilidade ou cristalização da matéria. Nos primeiros, a plasticidade da matéria não se dissocia da conservação da forma: eis aí o princípio de formação da vida. Ao contrário, no inorgânico, o que vigora é a modificação da forma; modificação esta que desorganiza e mortifica o corpo. Perguntamos assim: o jogo entre matéria e forma não criaria também um abismo entre o trabalho do físico e do biólogo, relegando o primeiro ao estudo da matéria, com suas leis gerais homogêneas e imutáveis, e ao segundo o estudo da forma e da variabilidade dos seres? E ao filósofo não caberia ir além, fazendo com que a vida e a morte não requeiram apenas explicações físicas e biológicas, mas também metafísicas?

\section{Referências}

BRANDÃO, E. A concepção de matéria na obra de Schopenhauer. São Paulo: Humanitas, 2008.

CACCIOLA, M. L. M. O. A crítica da razão no pensamento de Schopenhauer. Dissertação de mestrado. São Paulo: Universidade de São Paulo, 1981. . Schopenhauer e a questão do dogmatismo. São Paulo: Edusp, 1994.

JANET, P. Schopenhauer et la physiologie française. Cabanis et Bichat. In: Revue des deux mondes. Tome. 39. Paris: Bureau de la Reveu des deux mondes. 1er Mai 1880.

HUNEMAN, P. Métaphysique et biologie. Paris: Éditions Kimé, 2008.

LEBRUN, G. Kant e o Fim da Metafísica. Trad. Carlos Aberto Ribeiro de Moura. São Paulo, Martins Fontes, 1993.

PICHOT, A. Histoire de la notion de vie. Paris: Gallimard, 1993. 
ANA CAROLINA SOLIVA SORIA

ROGER, J. Les sciences de la vie dans la pensée française au XVIIIe siècle. Paris: Albin Michel, 1993.

SCHOPENHAUER, A. Sämtliche Werke in fünf Bänden. Hrsg. Wolfgang Frhr. Löhneysen. Stuttgart/Frankfurt am Main: Suhrkamp, 1986.

De la volonté dans la nature. Paris: Quadrige / PUF, 1996.

Recebido: $16 / 11 / 12$

Received: $11 / 16 / 12$

Aprovado: $13 / 12 / 12$

Approved: $12 / 13 / 12$ 